\title{
Validating Governance Performance Indicators for Integrated Coastal and Ocean Management in the Southeast Region of Cuba
}

\author{
Fajardo José Abelardo Planas', Batista Celene Milanés², Lucia M. Fanning³, \\ Camilo Mateo Botero 4 \\ ${ }^{1}$ Solar Energy Research Center, Micro III. C. Urbano Abel Santamaría, Santiago de Cuba, Cuba \\ ${ }^{2}$ Coastal Zone Multidisciplinary Studies Center, University of Oriente, Santiago de Cuba, Cuba \\ ${ }^{3}$ Marine Affairs Program, Dalhousie University, Halifax, Canada \\ ${ }^{4} J o a q u i n$ Aaron Manjarres Research Group, University Sergio Arboleda, Santa Marta, Colombia \\ Email: celene@uo.edu.cu
}

Received 14 October 2015; accepted 8 January 2016; published 12 January 2016

Copyright (C) 2016 by authors and Scientific Research Publishing Inc.

This work is licensed under the Creative Commons Attribution International License (CC BY). http://creativecommons.org/licenses/by/4.0/

(c) (i) Open Access

\begin{abstract}
The importance of evaluating the success of policies developed to effectively manage coastal and marine resource use is well documented. However, few frameworks exist that allow for a comparative examination of existing policy instruments, as opposed to specific initiatives, which assess governance performance aimed at addressing issues arising in the coastal zone. This paper describes the process and findings for evaluating the feasibility of a modified Coastal Sustainability Standard (CoSS) framework that seeks to measure the effectiveness of individual planning instruments within overlapping spatial boundaries in the landward and marine areas in the southeast region of Cuba. Through workshops conducted in Santiago de Cuba and Guamá municipalities with key representatives involved in coastal management and planning, the utility of the framework was assessed using the main instruments of territorial planning in Cuba, namely integrated river basin management, territorial planning in coastal municipalities and marine and coastal management. While, the findings suggest that the modified CoSS framework can be used to assess the effectiveness of these planning instruments in the region, and workshop participants also suggested improvements to better match its use to the characteristics of the study region.
\end{abstract}

\section{Keywords}

Governance, Planning Instruments, Integrated Coastal Zone Management, Southeast Cuba 


\section{Introduction}

Numerous studies over the past few decades have identified the fact that coastal zones throughout the world have become fragile and threatened ecosystems, posing threats to both the natural and human systems that depend on these areas for their sustenance [1]-[7]. Key drivers underpinning these changes include a growing global population base and the increasing impacts of global climate change and the associated pressures that these bring in terms of increasing competing demands for space and resources [8] [9]. Not surprising, these competing demands have the potential to generate numerous conflicts that are manifested at multiple spatial scales. For most coastal countries, these appear to congregate within the coastal areas under municipal, provincial/state and national levels of jurisdiction [10] [11]. As such, responses at both the operational and policy level have tended to focus on finding ways to minimize these conflicts while maximizing benefits [12].

For the southeast region of Cuba, the challenges confronting the coastal and marine areas and the people who inhabit the region appear to be further exacerbated by a lack of policy responses that effectively address both anthropogenic and nature-driven threats in a coherent manner. Specifically, the current model of planning and territorial management in the coastal municipalities of the eastern region of Cuba appear to be deficient in addressing a wide variety of threats, particularly those present in the local communities [13]. Some of these threats include the intensive use of the coastal areas for urban development; deforestation and soil erosion in river basins and coastal areas; the continuous rise of the sea level and coastal development in high risk areas vulnerable to earth slides, floods, erosion and desertification [14]. As such, there is an urgent need for research to inform policies aimed at helping these communities minimize and adapt to these threats, as called for in Cuba's National Environmental Strategy [15].

In Cuba, a number of territorial planning instruments currently exist. These focus on spatially-overlapping areas in the coastal zone and address integrated river basin management, territorial planning in coastal municipalities and marine and coastal management. However, their effectiveness appears hampered by a general disconnect between the instruments, despite their shared geographic area. Other possible factors include the lack of a systematic approach to enforce regulations and the interest and/or capacity of the responsible agencies to implement needed interventions that can meaningfully address problems in an integrated manner in the coastal areas. At the same time, the current arrangements also lack the appropriate governance structure that would facilitate greater stakeholder participation in the development of local area strategies. However, it needs to be said that these challenges are not unique to Cuba.

In referring to the governance of integrated coastal management, Ehler [16] noted the challenge to establish measurement systems able to adequately check the progress of efforts. Additionally, the Intergovernmental Oceanographic Commission, a body under the auspices of the United Nations Education, Scientific and Cultural Organization (UNESCO) stated that the sustainable development of coasts and oceans are also based on the premise that the management of those areas should be a collaborative effort among all the involved actors [17]. However, for planning and management instruments to be effective, they need to be understood by the communities located in the coastal areas as their success depends on the active participation of the actors involved in the management [18]-[20]. In addition, a substantial body of literature in integrated coastal management has noted that without harmonization and integration among government and the other state entities with responsibility for coastal areas, the ability to implement policies that support needed solutions is reduced [21]. Thus we posit that both the insufficient participation of the local population in coastal management and poor communication of plans and programs developed by governmental agencies can lead to ineffective policy outcomes and low compliance levels by the local population. This we argue is a reflection of the governance mechanisms in place, where governance is understood as the way in which the governments, institutions, markets and social organizations interact reciprocally with the citizens when they take the decisions [22]. Furthermore, as noted by Echevarría and colleagues [23], these interactions with citizens are a reflection in the way; powers are exercised according to principles of accessibility, participation, responsibility, effectiveness, coherence and proportionality.

Recognizing both the threats to and significance of the coastal resources to communities in southeast Cuba, this paper addresses the gap identified in the literature calling for an assessment of coastal governance performance aimed at a comparative examination of existing policies, as opposed to specific initiatives. It examines the feasibility of an indicator-based framework to evaluate the effectiveness of three spatially-overlapping coastal planning instruments in southeast Cuba. First, the paper focuses on a description of the proposed evaluation framework, based on a modification by the authors of the Coastal Sustainability Standard (CoSS) developed by Gallagher [24], and the three planning instruments used as test cases to determine the applicability of the 
framework. It then highlights the methodology for assessing the feasibility of the framework in southeast Cuba using two workshops with participants involved in coastal management from two municipalities in Santiago de Cuba province. This is followed by the results from the workshops and a discussion on the applicability of the framework, including recommendations for improvement of the framework as a governance evaluative tool by workshop participants.

\section{The Proposed Indicator-Based Framework}

The Coastal Sustainability Framework (CoSS) developed by Gallagher [24] and subsequently modified by the authors followed an extensive literature review on the use of indicators for evaluating integrated coastal zone management effectiveness and efficiency and their implementation in programs and strategies targeting local development in coastal areas. After reviewing a diverse selection of potentially suitable frameworks based on their suitability to evaluate governance performance in policy level instruments [25]-[31], the CoSS was identified as the best candidate for modification by the authors, despite its focus on assessing specific initiatives. As proposed by Gallagher [24], the framework centers around a suite of six principles or indicators (planning, participation, communication, integration, responsibility and balance) to be use in the rating of the specific initiatives of integrated coastal zone management effectiveness, defined on the basis of achieving stated objectives.

The planning principle measures the presence of clear objectives, having an iterative and adaptive process, effective monitoring and continuous improvement. The participation principle is based on common knowledge, interaction among stakeholders and contributions to the decision making process. The communication principle refers to free access and easy understanding of information, quality of data and a two-way process. The integration principle is related to an interdisciplinary approach, the complex understanding of coastal systems and coordinated decision making. The responsibility principle highlights risk assessment and the effectiveness of the legal framework. Lastly, the balance principle focuses on trade-offs made to achieve coastal sustainability.

The modified framework used by the authors incorporated Gallagher's six principles as indicators of governance effectiveness in implementing Cuban territorial planning instruments within the coastal zone of Cuba. However, a revised description of the indicators and ranking scheme was developed in order to identify both the weaknesses and strengths of the governance processes underlying the Cuban planning instruments. These are identified in Figure 1 as addressing integrated river basin management, territorial planning in coastal municipalities and marine and coastal planning.

\section{Territorial Planning Instruments in Cuba}

With a coastline spanning some 5980 kilometres, coastal and marine ecosystem goods and services are utilized by both traditional coastal communities and the productive sectors related to tourism, ports, sailing, fishing, and aquaculture, among others in Cuba [13]. The country has a deep tradition of Roman Law resulting in its decision making process being strongly dependent on a legal framework, public institutions and state apparati. A growing population density, increased industrial and touristic development, and the increasing degradation of the coastal (land and sea) environment are challenges confronting all regions in Cuba, including the province of Santiago de Cuba in the southeast [13].

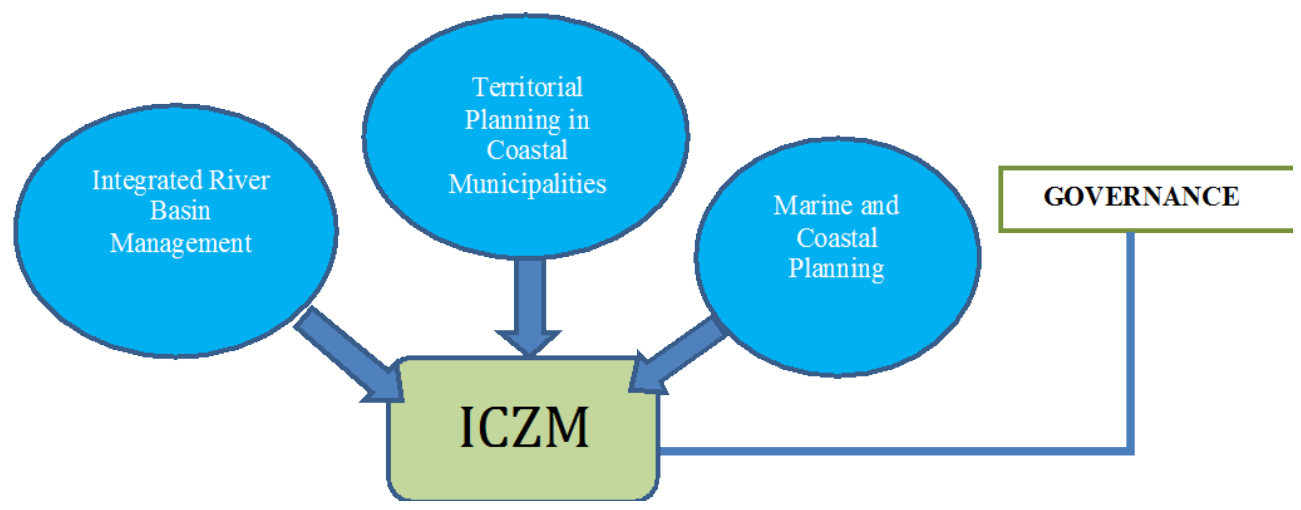

Figure 1. Overlapping instruments of territorial planning influencing governance processes in Cuba. 
Research into the spatially-based coastal planning approaches currently in place in Cuba identified the presence of legislation, policies and institutions for managing coastal resources and activities. The relevant policy level and legal instruments are highlighted in Table 1. For integrated river basin management, planning and implementation authority is provided under a general environmental policy and a single umbrella law covering all issues related with the environment. In Cuba, there is a general environmental policy and a specific procedure for integrated coastal management application. There is also a specific legislation for coastal management with one decree serving all coastal zone management issues as well as a general environmental law which applies to coastal areas. Finally, there is no specific legislation regarding the integrated management of marine areas in Cuba.

\section{Methodology for Assessing the Feasibility of the Proposed Framework}

The validation and application of the modified CoSS indicator framework was done through conducting two workshops in two distinct coastal areas within the province of Santiago de Cuba, namely Santiago de Cuba and Guamá municipalities (Figure 2).

These municipalities were selected based on their characteristically different yet significant management conflicts, involving current interests in the municipalities and the exploitation of their respective natural resources. Both areas have great interest in socioeconomic development and nature conservation. Participants in the two workshops used the modified CoSS framework to evaluate the performance of the six indicators in the three main instruments of territorial planning and the general performance of these instruments in two chosen districts: the Bay of Santiago de Cuba, and the coastal area of Guamá Municipality, which also included the Seville River basin as a study area.

The workshop participants included representatives of provincial and municipal institutions with experience in the current planning and management procedures in these territories, coming from institutions with responsibilities for local administration and territorial planning decisions making. In addition to identifying test areas

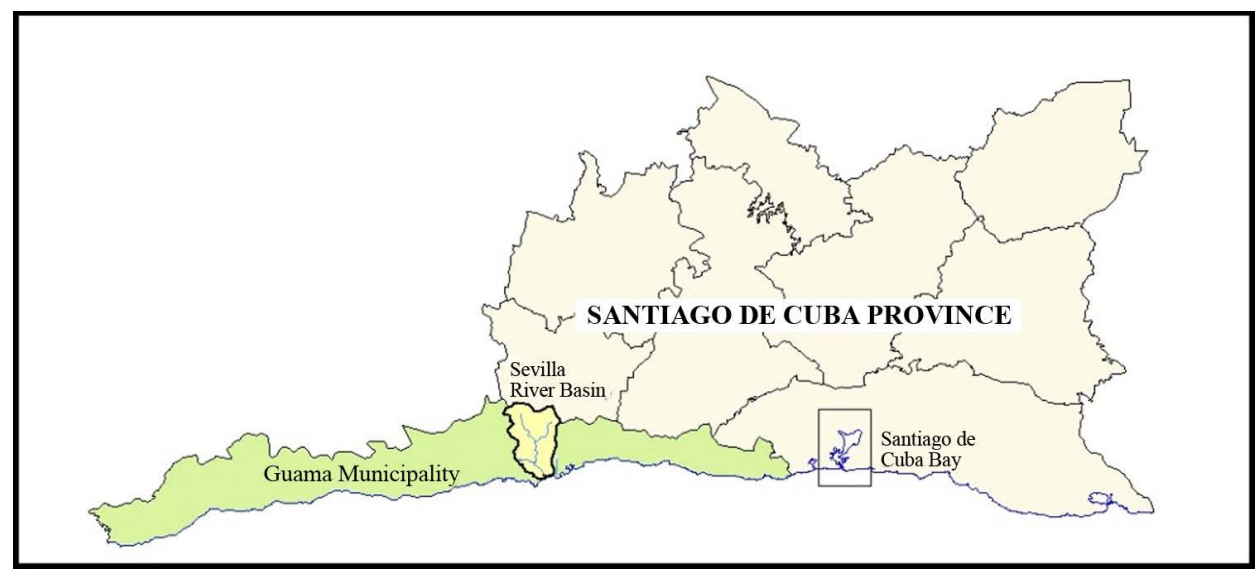

Figure 2. Coastal areas selected to test the feasibility of the modified Coastal Sustainability Standard (CoSS) framework.

Table 1. Policy and legislative framework of river basin management, territorial planning in coastal municipalities and coastal and marine planning in Cuba.

\begin{tabular}{|c|c|c|}
\hline Spatial Area & Policies & Legislation \\
\hline $\begin{array}{l}\text { River basin planning and } \\
\text { management }\end{array}$ & $\begin{array}{l}\text { Environmental National Policy (2010). National } \\
\text { Strategy of Environmental Education (2010-2015). }\end{array}$ & Law 81 (1997) “Environmental”. \\
\hline $\begin{array}{l}\text { Territorial planning and } \\
\text { management in coastal } \\
\text { municipalities }\end{array}$ & $\begin{array}{l}\text { Environmental National Policy (2010) National } \\
\text { Procedure to evaluate and approve Integrated Coastal } \\
\text { Zone Management process in Cuba (2007). }\end{array}$ & $\begin{array}{l}\text { Decree-Law 212/2000 “Coastal Management”; } \\
\text { Decree-Law } 21 \text { (1978). "Physical Planning”; } \\
\text { Decree } 299 \text { (2012) “Physical Planning } \\
\text { Institution”; Law } 81 \text { (1997) “Environmental”. }\end{array}$ \\
\hline $\begin{array}{l}\text { Coastal and marine areas } \\
\text { planning and management }\end{array}$ & $\begin{array}{l}\text { Environmental National Policy (2010) National } \\
\text { Strategy for Environmental Education (2010-2015). }\end{array}$ & $\begin{array}{l}\text { Law } 81 \text { (1997) “Environmental”; Decree-Law } \\
201 \text { (1999) National System of Protected Areas. }\end{array}$ \\
\hline
\end{tabular}


that were subject to all three of the planning instruments, each site was selected on the basis of having a greater focus with respect to one of the planning instruments (e.g. Santiago de Cuba Bay for marine and coastal planning; coastal area of Guamá Municipality for territorial planning in coastal municipalities and Seville River basin for integrated river basin management). Additionally, from a methodological perspective, participants at both workshops were asked to assess the feasibility of the framework to assess governance performance of the planning instruments for the coastal area of Guamá Municipality. This allowed for acomparison of the results obtained for this test site across the two workshops (Appendix 1).

In the Santiago de Cuba workshop, participants focused on testing the feasibility of the framework on the planning instruments as applied to coastal and marine area around Santiago de Cuba Bay and as mentioned above, the coastal areas of Guamá Municipality. The Bay is surrounded by the city of Santiago de Cuba, the second largest city in Cuba with a population of approximately 500,000 in 2012 [32]. The area is also home to the second largest industrial complex in Cuba and is a major seaport on the Caribbean coast. Several river basins surround the Bay resulting in strong pollutant loads coming from the land to the Bay. In addition to these pressures, the area is prone to natural disasters including hurricanes and earthquakes with little attention being paid to planning as a means of minimizing these risks, resulting in the critical infrastructure being located in vulnerable areas.

In the workshop held in Guamá municipality, representatives including those from municipal institutions evaluated the performance of the six indicators in the territorial planning instruments and the general performance of the instruments in two chosen areas, namely the municipality coastal area and the Seville River basin. The inclusion of the Seville River basin as an area to test the feasibility of the modified framework was based on the importance of agriculture and tourism development. The area has been identified as having great potential for tourist development, due to an abundance of natural wealth and attractive landscapes. However, as with Santiago de Cuba Bay, the area possesses high vulnerabilities associated to the risks from adverse natural phenomena increased by inappropriate coastal development resulting in erosion and other negative impacts on marine ecosystems.

The format of the two workshops was the same regardless of the location. First, the authors presented the modified CoSS framework to the participants, allowing for any questions relating to the six indicators and/or the ranking criteria to be raised. Participants were then divided into two groups. Each member of the group then had the opportunity to rank the performance of the governance processes for each of the three planning instruments addressing river basin management, territorial planning in coastal municipalities and coastal and marine management using each of the indicators. The criteria for scoring each of the six indicators are provided in Appendix 2.

The scoring system uses an ordinal scale ranging from zero to 10 similar to that used by Gallagher [24], with four points of reference to guide assessment of progress in a particular case: 0, 3, 7 and 10. The worst scenario is denoted with zero (0), although it does not necessarily imply "no progress", as it could result from a lack of knowledge by participants about core concepts and characteristics established in the scoring criteria associated with the respective indicator. A score of 10 is assigned to any indicator that completely addresses the CoSS principle. Intermediate scores show differing levels of progress with a value less than three $(<3)$ signaling the need for corrective action; values between three and seven represent efforts in progress to coastal sustainability, although several improvements are necessary; and values more than seven ( $>7)$ suggesting progress above the level of sustainability and close to ideal conditions. As the scoring is assigned for each planning instrument with its defined spatial boundary, information on the effectiveness of the different land and marine planning instruments as well as differences in the progress between each spatially-defined planning boundary is obtained.

Following the ranking by participants in each group, the individual scores for each indicator were averaged. The results were then analyzed and interpreted, to determine the overall level of effectiveness based on expert opinion for each planning instrument in the selected coastal areas. The findings from each of the two teams were then discussed in a plenary session. This led to wide ranging contributions of ideas, critiques and approaches of great practical value that, in addition to clarifying points of views and opinions on the instruments, allowed for the identification of the strengths and weaknesses of the proposed framework for assessing governance effectiveness of the planning instruments.

\section{Results}

The results of the criteria evaluation from the two groups of workshop participants knowledgeable in applying 
the planning instruments and their assigned level of performance within the respective study areas are presented below. The workshop results from the participants that met in Santiago de Cuba are presented in Table 2 (for Santiago de Cuba Bay) and Table 3 (for coastal areas of Guamá Municipality. Complementing the tabular results for each test site are graphical illustrations of the finding in the form of a kite diagram showing the rankings for all six indicators for each of the three planning instruments for Santiago de Cuba Bay (Figure 3) and for the coastal areas of Guamá Municipality (Figure 4). Similar presentations of results are provided for the workshop that was held in Guamá for the coastal areas of Guamá Municipality (Table 4 and Figure 5) and the Seville River basin (Table 5 and Figure 6).

\section{Discussion and Recommendations}

In terms of the actual ranking of governance performance by the workshop participants, there were some differ-

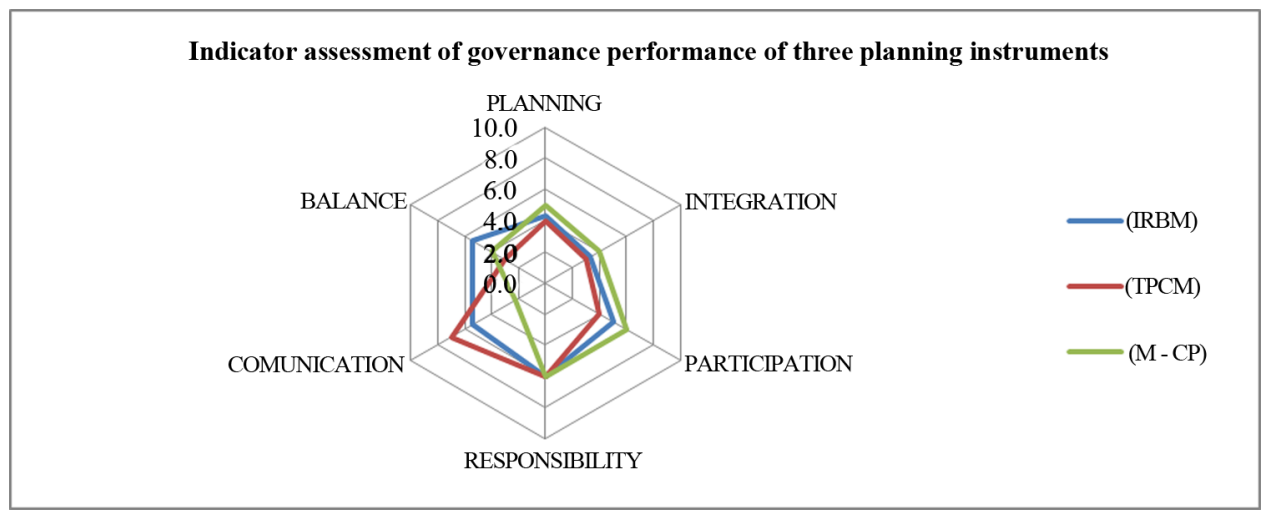

Figure 3. Comparison of ranking for governance performance of each of three planning instruments by Santiago de Cuba workshop participants for Santiago de Cuba Bay.

Table 2. Aggregate scoring results of the six indicators to evaluate governance performance of planning instruments in Santiago de Cuba Bay by Santiago de Cuba workshop participants.

\begin{tabular}{llll}
\hline Indicators & $\begin{array}{l}\text { Integrated River Basin } \\
\text { Management (IRBM) }\end{array}$ & $\begin{array}{l}\text { Territorial Planning in Coastal } \\
\text { Municipalities (TPCM) }\end{array}$ & $\begin{array}{l}\text { Marine and Coastal Planning } \\
\text { (M-CP) }\end{array}$ \\
\hline Planning & 4.3 & 4 & 5 \\
Integration & 3.3 & 3 & 4 \\
Participation & 5 & 4 & 6 \\
Responsibility & 6 & 6 & 6 \\
Communication & 5.4 & 7 & 2.2 \\
Balance & 5.4 & 3 & 4 \\
\hline
\end{tabular}

Table 3. Aggregate scoring results of the six indicators to evaluate governance performance of planning instruments in coastal areas of Guamá municipality by Santiago de Cuba workshop participants.

\begin{tabular}{llll}
\hline Indicators-principles & $\begin{array}{l}\text { Integrated River Basin } \\
\text { Managements (IRBM) }\end{array}$ & $\begin{array}{l}\text { Territorial Planning in Coastal } \\
\text { Municipalities (TPCM) }\end{array}$ & $\begin{array}{l}\text { Marine and Coastal } \\
\text { Planning (M- CP) }\end{array}$ \\
\hline Planning & 6.8 & 7.5 & 3 \\
Integration & 7 & 6 & 3 \\
Participation & 6 & 7 & 5 \\
Responsibility & 3 & 9.2 & 4.7 \\
Communication & 7.5 & 7 & 2.5 \\
Balance & 5.2 & 7.5 & 3.2 \\
\hline
\end{tabular}




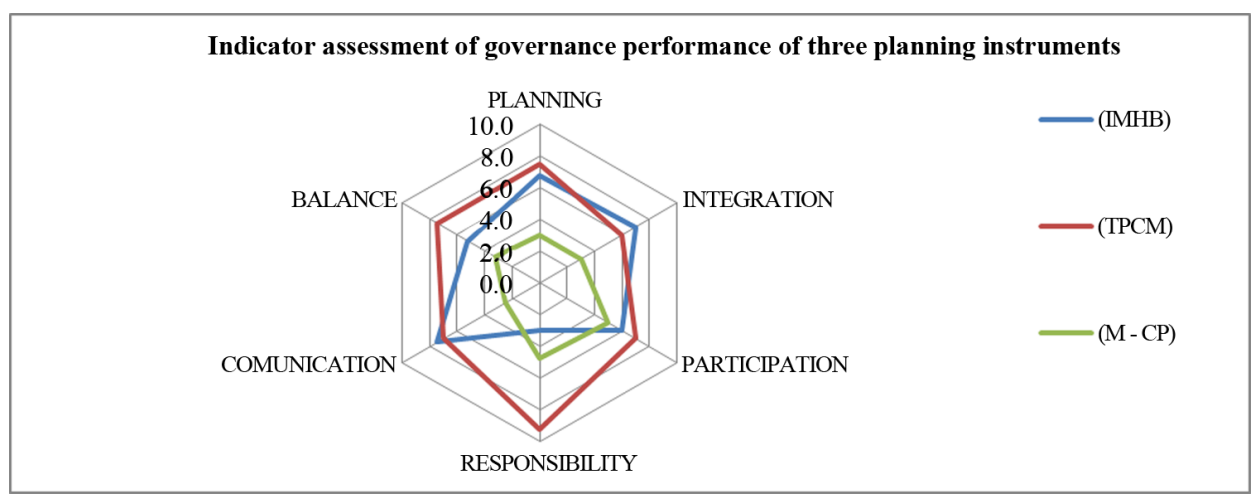

Figure 4. Comparison of ranking for governance performance of each of three planning instruments by Santiago de Cuba workshop participants for coastal areas of Guamá municipality.

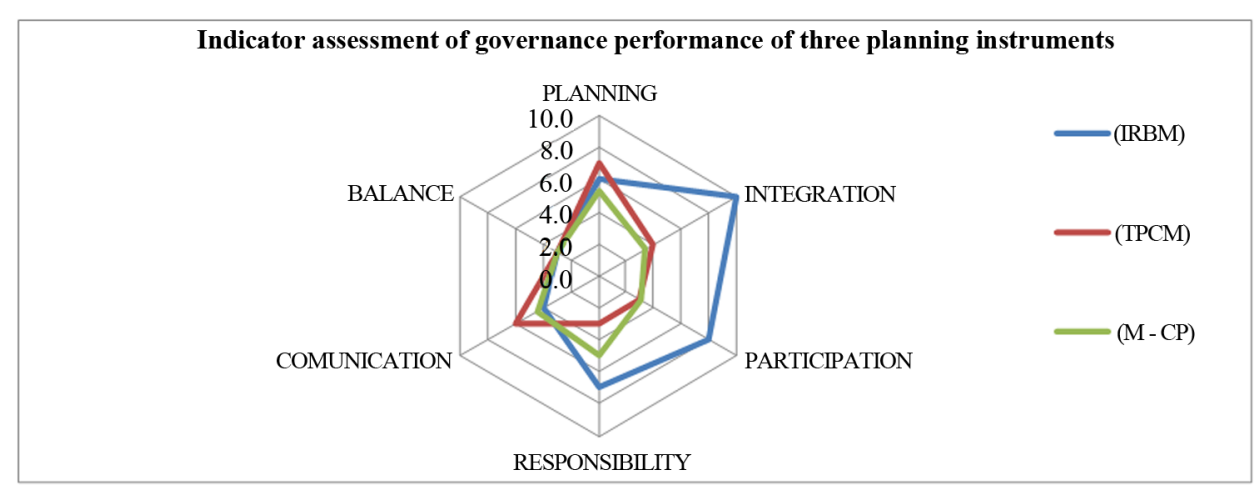

Figure 5. Comparison of ranking for governance performance of each of three planning instruments by Guamá workshop participants for coastal areas of Guamá municipality.

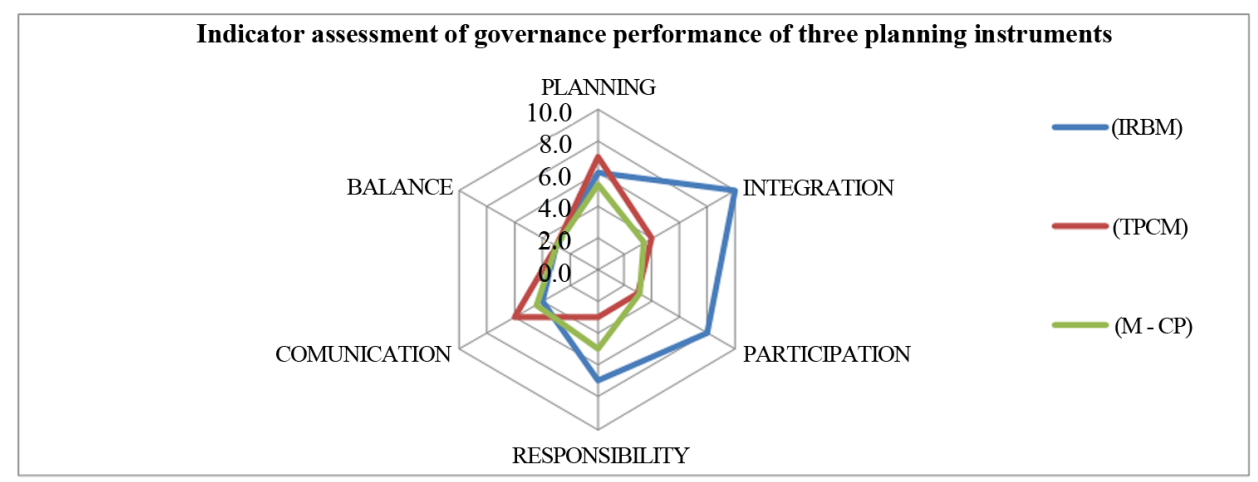

Figure 6. Comparison of ranking for governance performance of each of three planning instruments by Guamá workshop participants for Seville river basin.

ences observed between the assessment for Santiago de Cuba Bay as compared to the coastal areas of Guamá Municipality and the Seville River basin.

\subsection{Santiago de Cuba Workshop}

Participants at the workshop in Santiago de Cuba assessed all three planning instruments to have a governance performance level ranging between a score of 3 and 7 for Santiago de Cuba Bay, with the exception of a low score of 2.25 for the communication indicator for the Marine and Coastal Planning instrument (Table 2 and Figure 3). These rankings suggest that in general, all three instruments were making some progress with respect to governance performance but there was still considerable room for improvement. Most noticeably, integration 
Table 4. Aggregate scoring results of the six indicators to evaluate governance performance of planning instruments in coastal areas of Guamá municipality.

\begin{tabular}{llll}
\hline Indicators-Principles & $\begin{array}{l}\text { Integrated River Basin } \\
\text { Managements (IRBM) }\end{array}$ & $\begin{array}{l}\text { Territorial Planning in Coastal } \\
\text { Municipalities (TPCM) }\end{array}$ & $\begin{array}{l}\text { Marine and Coastal } \\
\text { Planning (M-CP) }\end{array}$ \\
\hline Planning & 6.0 & 7 & 5.3 \\
Integration & 10 & 4 & 3.4 \\
Participation & 8 & 3 & 3.0 \\
Responsibility & 7 & 3 & 5 \\
Communication & 4 & 6 & 4.4 \\
Balance & 3 & 3 & 3 \\
\hline
\end{tabular}

Table 5. Aggregate scoring results of the six indicators to evaluate governance performance of planning instruments in Seville River basin.

\begin{tabular}{llll}
\hline Indicators-Principles & $\begin{array}{l}\text { Integrated River Basin } \\
\text { Managements (IRBM) }\end{array}$ & $\begin{array}{l}\text { Territorial Planning in Coastal } \\
\text { Municipalities (TPCM) }\end{array}$ & $\begin{array}{l}\text { Marine and Coastal } \\
\text { Planning (M-CP) }\end{array}$ \\
\hline Planning & 4.0 & 4.5 & 7 \\
Integration & 4 & 3 & 4 \\
Participation & 3 & 2.6 & 2.2 \\
Responsibility & 6.5 & 7 & 7 \\
Communication & 7 & 6 & 7 \\
Balance & 7 & 6 & 7 \\
\hline
\end{tabular}

as an indicator received the lowest overall score among the three planning instruments, suggesting that participants still viewed these instruments as being implemented in an isolated, spatially separated manner. In terms of the highest score, this was attributed to the communication indicator for the territorial planning in coastal municipalities, possibly due to the fact that many of the practitioners implementing this instrument had very good connections with the community stakeholders.

With regard to the assessment of the coastal areas of Guamá Municipality, participants displayed the greatest diversity in scoring across the three planning instruments (Table 3 and Figure 4). The territorial planning for coastal municipalities received an overall score across the six indicators that suggested governance performance for this planning instrument was well above average and in fact, the participants scored the indicator relating to responsibility, associated with risk assessment and the effectiveness of the legal framework, as almost perfect. Again, we attribute the high ranking to the close linkage between the planning occurring at the level of the municipality and the connectivity and knowledge of those with responsibility for implementing the planning instrument within the coastal areas. In contrast, this same indicator was scored the lowest for the Integrated River Basin Management instrument, receiving a score that suggests river basin management is considered to have an insufficient legal basis for coastal areas and even when risk assessments is conducted, it is generally superficial. Furthermore, organizations involved in ICZM in river basins appear to be indifferent to stewardship and resource efficiency. Finally, the planning instrument for marine and coastal planning received an overall score of just above 3 out of 10, implying a need for considerable corrective action if governance performance is to be enhanced.

\subsection{Guamá Municipality Workshop}

Participants at the Guamá municipality workshop scored all three planning instruments to be between a score of 4 and 7 for the coastal areas, suggesting that there was considerable need for improvement in governance performance among all of the instruments (Table 4 and Figure 5). However, unlike the participants at the Santiago workshop, these participants ranked the instrument for Integrated River Basin Management to be the highest at an overall average score of 6.3 , while scoring the other two planning instruments similarly at a level that was 
well below average. It should be noted however that there was relatively little difference in the scores for IRBM between the two workshop participants (5.9 versus 6.3). Rather the more significant difference seemed to be in the assessment for the territorial planning for coastal areas where the Santiago de Cuba workshop participants scored governance performance to be above average with an overall score of 7.4 while the Guamá municipality workshop participants scored governance performance of the same instrument at 4.3. This discrepancy could be due to the better familiarity if the Guamá municipality participants with the implementation of the instrument in their coastal areas, providing a more realistic, albeit lower score, for this instrument than the Santiago de Cuba participants. Finally, it is worth noting that the participants scored the balance indicator as the lowest among all six indicators, with all three of the planning instruments receiving a score of 3 . This suggests that they saw an almost total lack of "social fairness" as a principle influencing decisions relating to coastal planning in the areas along with little attention paid to conducting costs and benefits analysis to inform decision making.

In terms of assessing the governance performance of the planning instruments in the Seville River basin area, the scoring results showed little diversity across the three instruments, ranging from 4.8 to 5.7 (Table 5 and Figure 6). As with the other assessments, these rankings recognize that some progress towards governance performance has been made but that there is still considerable room for improvement. Most noticeably, the scored for participation were the lowest across the three planning instruments, highlighting the urgent need to address this important governance principle if integrated coastal zone management is to be successful. Furthermore, the scoring indicates a very small number of stakeholders are aware or interested in the management of the three spatially connected geographic areas and that when stakeholders do participate, they generally play a passive or reactive role in solutions designed to alleviate pressures confronting the coastal areas.

\subsection{Recommendations}

In terms of addressing the feasibility of the framework having worked through it, participants from both workshops offered the following recommendations for improvement:

1) In terms of the scoring criteria, participants recommended including a mid-point score of " 5 " between the scores of 3 and 7 as it would allow for a better discrimination and characterization of the possible performance levels, rather than forcing the assessor to either give a lower (3) or higher (7) score than what they realistically would like to assign.

2) The participants also called for the inclusion of a seventh new indicator that focuses on assessing mechanisms for implementation in the planning instruments. This was seen as essential to assess governance performance in terms of having the ability to both be accountable for implementation and to institute good governance practice that would require the monitoring and evaluation of decisions with regard to their implementation. Additionally, the implementation indicator should also be used to measure the use of each of the planning instruments in the different coastal areas to assess the level of integrated coastal zone management across these overlapping spatial areas.

3) A third recommendation from participants focused on the development of more quantitative measures to assess governance performance progress, complementing the proposed qualitative assessment. For example, having an objective indicator that assesses the participation indicator in a way that looks at the number of meetings that sought participation among those involved in each of the planning instruments could focus the need for interventions and contribute to improving efforts at participation over time.

It is important to note that the participants at the two workshops included representatives of the provincial and local government authorities with responsibilities for implementing the planning instruments. By evaluating the effectiveness of the governance processes in place for river basins, territorial planning at the municipal level and coastal and marine management themselves, these government experts are able to understand directly the weaknesses and strengths of the planning instruments they are responsible for, with respect to each of the six indicators. As such, their ability to influence changes in the governance processes arises as a direct result of their participation in the evaluation of the effectiveness of the instruments they are implementing. We suggest that this direct involvement in the evaluation of the methodology by the government experts has a great opportunity for influencing policy and generating change that improves governance processes associated with overlapping spatial instruments in the coastal areas of southeast Cuba.

In accounting for his findings when conducting the CoSS analysis for specific ICZM initiatives, Gallagher [24] postulated three propositions to explain why none of the two cases he evaluated met the CoSS ranking of 7 that 
had been assigned as meeting a measure for success. These were listed as a failure of the standard to reflect ICZM and its goal of achieving sustainable development, that the scoring and appraisal process was incorrect or inaccurate and that there were inherent shortcomings in integrated coastal management that impact on the ability of the specific initiatives to achieve their goals. He concluded that only the last proposition, an inherent failure in the way ICZM was implemented, could account for the failure of the initiatives he had assessed.

Our research findings focusing on the feasibility of the framework in the southeast of Cuba, tend to support Gallagher's conclusion regarding the first proposition. This was noted despite the modification of the framework to focus on governance processes rather than specific initiatives. As with the case studies focusing in the United Kingdom [24], our findings suggest that the methodology was appropriate to assessing the outcomes that underpinned the development and implementation of the planning instruments. Our findings on this proposition also contribute to the call that the methodology be trialed outside of the United Kingdom.

However, with regard to the second proposition on the validity of the scoring mechanism and the analysis of the appraisal process, our results differ from those of the study in the United Kingdom. Even with putting in place all of the methodological guidance recommended by Gallagher [24] and holding workshops that detailed the process with the participants conducting the assessment, the scoring criteria were found to be inadequate. Additionally as noted in the recommendations, participants also called for additional indicator focusing on implementation and accountability. These differences in our findings may be due to the emphasis in our study on governance performance of the planning instruments themselves rather than the specific initiatives being assessed in the United Kingdom study and the high degree of local level knowledge held by the participants in our study of the areas being used as study sites.

Finally in terms of the third proposition suggested by Gallaher [24] to explain his results, namely "that poor performance must be a result of 'inherent shortcomings in ICZM that impact on the ability of CPs to achieve their aims'” (p342), it is more difficult to directly compare our findings with those of Gallagher, given the difference what was being assessed in the two studies. However, our results clearly support the conclusion that principles of planning, integration, participation, responsibility communication and balance need to be integrated into the structure or architecture of the planning instruments themselves as a means of ensuring the "fit" of the governing instrument with its expected goals [24].

\section{Conclusions}

The modified Coastal Sustainability Standard (CoSS) framework focusing on governance performance of planning instruments in the southeast area of Cuba, as opposed to specific initiatives, demonstrated its applicability by highlighting areas for improvement in achieving goals for integrated coastal zone management in the southeast region of Cuba. Overall, in terms of the applicability of the modified framework, the expert participants in the two workshops concluded that the procedure seems to be very useful in helping to evaluate the effectiveness of the instruments of territorial planning in Cuba. While recommendations for improvement were offered, the process to undertake the evaluation was seen as facilitating a participative and inclusive way for identifying areas for improvement in managing issues affecting overlapping spatial areas in the coastal zone. This was viewed as instrumental in enhancing the existing governance processes and supporting the development of agreed strategies with local actors who have vested interests in the coastal area.

Participants were unanimous in their recommendations for specific improvements relating to the sharing of information relative to the three planning instruments giving their degree of spatial overlap in the coastal areas and for more inclusion of coastal stakeholders in decision making. This was seen as contributing to both enhancing compliance and legitimacy of the decisions being made and ensuring accountability by the agencies and organizations involved in implementation. Furthermore, by having a framework that assesses the planning instruments in a comparative manner, the potential for greater integration among the different planning processes and specialists associated with integrated river basin management, municipal planning for coastal communities and marine and coastal management can be enhanced. This is seen as critical if the benefits of integrated coastal management are obtained.

\section{Acknowledgements}

We acknowledge the Association of Universities and Colleges of Canada for funding the project entitled "Indicadores de efectividad en la planificación territorial, gobernabilidad y gestiónintegrada de la zonacostera del 
oriente de Cuba y el Caribe colombiano” as part of its funding of the Canada-Latin America and the Caribbean Research Exchange Grants.

\section{References}

[1] Barragán, J.M. (2003) Medio Ambiente y Desarrollo en Areas Litorales. Publicaciones Universidad de Cádiz, Cádiz.

[2] Cicin-Sain, B. and Knecht, R.W. (1998) Integrated Coastal and Ocean Management: Concepts and Practices. Island Press, Washington DC.

[3] Clark, J.R., Ed. (1995) Coastal Zone Management Handbook. CRC Press, Boca Raton.

[4] Crain, C.M., Halpern, B.S., Beck, M.W. and Kappel, C.V. (2009) Understanding and Managing Human Threats to the Coastal Marine Environment. Annals of the New York Academy of Sciences, 1162, 39-62. http://dx.doi.org/10.1111/j.1749-6632.2009.04496.x

[5] GESAMP (2001) A Sea of Troubles, Reports and Studies No. 70. United Nations Environment Program (UNEP), Nairobi.

[6] Halpern, B.S., Selkoe, K.A., Micheli, F. and Kappel, C.V. (2007) Evaluating and Ranking the Vulnerability of Global Marine Ecosystems to Anthropogenic Threats. Conservation Biology, 21, 1301-1315. http://dx.doi.org/10.1111/j.1523-1739.2007.00752.x

[7] Robinson, N.A. (1993) Agenda 21: Earth’s Action Plan. Oceana Publications, Inc., New York.

[8] Allen, M. R., et al. (2014) IPCC Fifth Assessment Synthesis Report-Climate Change 2014 Synthesis Report.

[9] Halpern, B.S., et al. (2012) An Index to Assess the Health and Benefits of the Global Ocean. Nature, 488, 615-620. http://dx.doi.org/10.1038/nature11397

[10] Cheong, S.-M. (2008) Controlling the Coast. Ocean and Coastal Management, 51, 391-396. http://dx.doi.org/10.1016/j.ocecoaman.2008.01.003

[11] Weinstein, M.P., et al. (2007) Managing Coastal Resources in the 21st Century. Frontiers in Ecology and the Environment, 5, 43-48. http://dx.doi.org/10.1890/1540-9295(2007)5[43:MCRITS]2.0.CO;2

[12] Post, J.C. and Lundin, C.G. (1996) Guidelines for Integrated Coastal Zone Management. World Bank, Washington DC. http://dx.doi.org/10.1596/0-8213-3735-1

[13] Milanes, C. (2014) Método integrado para demarcar y delimitar las zonas costeras (DOMIZC): Estudio del caso de Santiago de Cuba. Ph.D. Thesis, Universidad de Oriente, Santiago de Cuba.

[14] Planas, F.J.A. (2012) Indicadores Locales de Sostenibilidad para el Manejo Energético Ambiental en la Zona Costera de la Región Suroriental de Cuba. Ph.D. Thesis, Instituto de Geografía Tropical, Ministerio de Ciencia, Tecnología y Medio Ambiente.

[15] Government of Cuba (2007) Estrategia Ambiental Nacional (EAN 2007-2010). http://www.lib.utexas.edu/benson/lagovdocs/cuba/federal/ciencia/EstrategiaAmbientalNacional/estrategia.html

[16] Ehler, C.N. (2003) Indicators to Measure Governance Performance in Integrated Coastal Management. Ocean and Coastal Management, 46, 335-345. http://dx.doi.org/10.1016/S0964-5691(03)00020-6

[17] UNESCO (2006) A Handbook for Measuring the Progress and Outcomes of Integrated Coastal and Ocean Management. IOC Manuals and Guides 46, ICAM Dossier, 2, Paris.

[18] Sorensen, J. (1997) National and International Efforts at Integrated Coastal Management: Definitions, Achievements, and Lessons. Coastal Management, 25, 3-41. http://dx.doi.org/10.1080/08920759709362308

[19] Crabbe, M.J.C. (2014) Capacity Building and Policy Development in Belize Marine Protected Areas, an Example for Caribbean Integrated Coastal Management. International Journal of Tropical Biology and Conservation, 62, $287-291$.

[20] Ramsey, V., Cooper, J.A.G. and Yates, K.L. (2015) Integrated Coastal Zone Management and Its Potential Application to Antigua and Barbuda. Ocean \& Coastal Management, 118, 259-274. http://www.sciencedirect.com/science/article/pii/S0964569115001246

[21] Levy, J.P. (1993) A National Ocean Policy: An Elusive Quest. Marine Policy, 17, 75-80. http://dx.doi.org/10.1016/0308-597X(93)90023-V

[22] European Commission (2001) Comisión Europea. La Unión Europea Apuesta por las Zonas Costeras. Luxemburgo: Ofic. Publicaciones Oficiales de las Comunidades Europeas. http://ec.europa.eu/environment/iczm/pdf/2000brochure_es.pdf

[23] Echevarría, L., Gómez, A., Piriz, C., Quintas, C., Tejera, R. and Conde, D. (2013) Capacity Building for Local Coastal Managers: A Participatory Approach for Integrated Coastal and Marine Zones Management in Uruguay. Journal of Integrated Coastal Zone Management, 13, 445-456. http://dx.doi.org/10.5894/rgci402 
[24] Gallagher, A. (2010) The Coastal Sustainability Standard: A Management Systems Approach to ICZM. Ocean \& Coastal Management, 53, 336-349. http://dx.doi.org/10.1016/j.ocecoaman.2010.04.017

[25] Bowen, R.E. and Riley, C. (2003) Socio-Economic Indicators and Integrated Coastal Management. Ocean \& Coastal Management, 46, 299-312. http://dx.doi.org/10.1016/S0964-5691(03)00008-5

[26] Bille, R. (2007) A Dual-Level Framework for Evaluating Integrated Coastal Management beyond Labels. Ocean \& Coastal Management, 50, 796-807. http://dx.doi.org/10.1016/j.ocecoaman.2007.01.002

[27] Areizaga, J., Sanò, M., Medina, R. and Juanes, J. (2012) A Methodological Approach to Evaluate Progress and Public Participation in ICZM: The Case of the Cantabria Region, Spain. Ocean \& Coastal Management, 59, 63-76. http://dx.doi.org/10.1016/j.ocecoaman.2011.12.007

[28] Olsen, S.B. (2003) Frameworks and Indicators for Assessing Progress in Integrated Coastal Management Initiatives. Ocean \& Coastal Management, 46, 347-361. http://dx.doi.org/10.1016/S0964-5691(03)00012-7

[29] Henocque, Y. (2003) Development of Process Indicators for Coastal Zone Management Assessment in France. Ocean \& Coastal Management, 46, 363-379. http://dx.doi.org/10.1016/S0964-5691(03)00013-9

[30] Shipman, B. and Stojanovic, T. (2007) Facts, Fictions and Failures of Integrated Coastal Zone Management in Europe. Coastal Management, 35, 375-398. http://dx.doi.org/10.1080/08920750601169659

[31] Pickaver, A.H., Gilbert, C. and Breton, F. (2004) An Indicator Set to Measure the Progress in the Implementation of Integrated Coastal Zone Management in Europe. Ocean \& Coastal Management, 47, 449-462. http://dx.doi.org/10.1016/j.ocecoaman.2004.06.001

[32] Population Statistics for Cities (2015). http://www.citypopulation.de/php/cuba-admin.php?adm2id=3406 


\section{Appendix}

\begin{tabular}{|c|c|c|c|}
\hline \multirow[b]{2}{*}{ Institutions } & \multicolumn{2}{|c|}{ Municipality } & \multirow[b]{2}{*}{ Coastal Management Responsibility } \\
\hline & $\begin{array}{l}\text { Santiago } \\
\text { de Cuba }\end{array}$ & Guamá & \\
\hline Institute of Physical Planning (MPE) & 3 & 2 & Territorial planning \\
\hline $\begin{array}{l}\text { Multidisciplinary Coastal Zone Studies Center, } \\
\text { Oriente University }\end{array}$ & 4 & 1 & Research and capacity building \\
\hline $\begin{array}{l}\text { Provincial Environmental Unit, Ministry of } \\
\text { Science Technology and Environment }\end{array}$ & 3 & 1 & $\begin{array}{l}\text { Environmental management and control of } \\
\text { environmental legislation, compliance and enforcement }\end{array}$ \\
\hline $\begin{array}{l}\text { Solar Energy Research Center, } \\
\text { Ministry of Science Technology and Environment }\end{array}$ & 5 & 1 & Research, capacity building and technology transfer \\
\hline $\begin{array}{l}\text { Oriental Biodiversity and Ecosystems Center, } \\
\text { Ministry of Science Technology and Environment }\end{array}$ & 3 & & $\begin{array}{l}\text { Research, capacity building and protected natural area } \\
\text { management }\end{array}$ \\
\hline National Seismological Center & 1 & & Disaster risk research and capacity building \\
\hline $\begin{array}{l}\text { Provincial Office for the Patrimonial/Heritage } \\
\text { Restoration and Conservation }\end{array}$ & 1 & & $\begin{array}{l}\text { Environmental management and patrimonial/heritage } \\
\text { conservation }\end{array}$ \\
\hline National Institute of Water Resources & 1 & 1 & Hydrographic basins and water management \\
\hline Municipal University of Guamá & & 10 & Research and capacity building \\
\hline Government of Guamá Municipality & & 2 & $\begin{array}{l}\text { To plan and administer resources and make decisions } \\
\text { affecting the municipality }\end{array}$ \\
\hline Dalhousie University (Canada) & & 1 & Research and capacity building \\
\hline
\end{tabular}

Appendix 2.1. Scoring criteria for modified CoSS framework indicator: planning.

\begin{tabular}{ccc} 
& & Planning Instruments \\
\hline \multirow{2}{*}{ Scoring } & $\begin{array}{c}\text { Integrated Management of } \\
\text { Hydrographic Basins }\end{array}$ & $\begin{array}{c}\text { Territorial Planning in Coastal } \\
\text { Municipalities }\end{array}$ \\
\cline { 2 - 4 } & & Marine and Coastal Planning
\end{tabular}

The planning system does not address the integration of environmental protection, sociocultural issues and economic resources. No specific or clearly marked spatial boundary of the coastal area exists or is considered.

There is no coherent organizational

0 management structure. No objectives nor scale of work are defined. Activities not are focused on the most significant issues facing coastal sustainability. The management plan is not clearly linked to a system of feedback and interactive reflection. No evidence of a commitment to continually improve.
The land use planning instrument does not address does not address the integration of the integration of environmental protection,

environmental protection, sociocultural issues so and economic resources. No specific or clearly specific or clearly marked spatial boundary of the marked spatial boundary of the coastal area coastal area exists or is considered. There is no exists or is considered. There is no coherent coherent organizational management structure. No organizational management structure. No objectives nor scale of work are defined. Activities objectives nor scale of work are defined. not are focused on the most significant issues Activities not are focused on the most facing coastal sustainability. The management plan significant issues facing coastal sustainability. is not clearly linked to a system of feedback and The management plan is not clearly linked to a interactive reflection. No evidence of a commitment to continually improve. system of feedback and interactive reflection. No evidence of a commitment to continually improve.

The planning system is consistent with the protection of natural resources, but there is no attempt at integrating sociocultural and economic processes. The spatial boundary area has been considered though it is not clearly defined. There is some attempt at an

3 organizational management structure. Some objectives and scale of works are defined. Some objectives are focused on the most significant issues facing coastal sustainability. The management plan provides some linkage to a system of feedback and iterative reflection but it rarely happens. No evidence of a commitment to continually improve.
The land use planning instrument is consistent with the protection of natural resources, but there is no attempt at integrating sociocultural and economic processes. The spatial boundary area has been considered though it is not clearly defined. There is some attempt at an organizational management structure. Some objectives and scale of works are defined. Some objectives are focused on the most significant issues facing coastal sustainability. The management plan provides some linkage to a system of feedback and iterative reflection but it rarely happens. No evidence of a commitment to continually improve.
The marine and coastal planning instrument is consistent with the protection of natural resources, but there is no attempt at integrating sociocultural and economic processes. The spatial boundary area has been considered though it is not clearly defined. There is some attempt at an organizational management structure. Some objectives and scale of works are defined. Some objectives are focused on the most significant issues facing coastal sustainability. The management plan provides iterative reflection. No evidence of a commitment to continually improve. some linkage to a system of feedback and 


\section{Continued}

The planning system is consistent with the protection of natural and economic resources, but there is no attempt at integrating sociocultural processes. The spatial boundary area is clearly defined but does not include all of the relevant natural and anthropogenic activities. There is a coherent organizational

7 management structure. Most objectives and scale of works are defined. Objectives are mostly focused on the most significant issues facing coastal sustainability. The management plan is linked to a feedback and iterative reflection system that is used most of the time. No evidence of a commitment to continually improve.

Boundaries of river basins planning instruments are clearly defined and they are fully supportive of an integrated socio-ecological coastal system. The objectives of the planning system and its scale of work are clearly defined, and they include the most significant issues facing coastal sustainability. Plans for river basin management are continually improving with feedback and iterative assessment to adapt themselves to coastal conditions.
The territorial planning instrument is consistent with the protection of natural and economic resources, but there is no attempt at integrating sociocultural processes. The spatial boundary are is clearly defined but does not include all of the relevant natural and anthropogenic activities. There is a coherent organizational management structure. Most objectives and scale of works are defined. Objectives are mostly focused on the mos significant issues facing coastal sustainability. The management plan is linked to a feedback and iterative reflection system that is used most of the time. No evidence of a commitment to continually improve.

The planning instrument is consistent with the integration of socio-ecological coastal systems. The spatial boundary area in the land and sea is clearly defined and fully relevant to all kinds of processes and activities. There are coherent organizational structures to support coastal management. The objectives of the system and scale of works are defined and focused on the most significant issues facing coastal management. The objectives of the system and system of feedback and iterative reflection. There coastal sustainability. There is evidence of a is evidence of a commitment to continually improve.
Marine and coastal planning is consistent with natural and economic resources protection, but there is no attempt at integrating sociocultural processes. The spatial boundary area is clearly defined but does not include all of the relevant natural and anthropogenic activities. There is a coherent organizational management structure. Most objectives and scale of works are defined. Objectives are mostly focused on the most significant issues facing coastal sustainability. The management plan is linked to a feedback of the time. No evidence of a commitment to continually improve.

The planning is consistent with the integration of natural, economic and sociocultural resources. The spatial boundary area in the land and sea is clearly defined and fully relevant to all kinds of processes and activities. There are coherent organizational structures to coastal focused on the most significant issues facing commitment to continually improve.

\section{Appendix 2.2. Scoring criteria for modified CoSS framework indicator: integration.}

\begin{tabular}{ccc}
\hline & & \multicolumn{1}{c}{ Planning Instruments } \\
\cline { 2 - 3 } Scoring & $\begin{array}{c}\text { Integrated Management of } \\
\text { Hydrographic Basins }\end{array}$ & Territorial Planning in Coastal Municipalities \\
\hline
\end{tabular}

Integrated Management of hydrographic basins has a strong sectorial approach, with dominance of one or two disciplines; management units and sectors within the river basin are unequal in decision making; solutions are proposed from a sectorial perspective, avoiding systems analysis and recognition of coastal complexity within the river basin.

Hydrographic basin management has some multi-sectorial or multi-level coordination actions; few disciplines have clear opportunities to influence decision making an there is variability among management units and sectors placed with the river basin; solutions are very rarely proposed from an integrated or interdisciplinary way, ignoring complexity of coastal component of the river basin.

Hydrographic basin management has multi-sectorial or multi-level coordination, but rarely both; there are several efforts aimed at supporting equality of opportunities in the decision making among the different

7 disciplines, management units and sectors within the river basin; solutions usually are proposed from an integrated and interdisciplinary way, although they are rarely based on systems analysis of coastal complexity.

Marine and coastal planning has a strong Land use planning in coastal municipalities has a strong sectorial approach, with dominance of one sectorial approach, with dominance of one or two or two disciplines; management units and disciplines; management units and sectors placed within sectors placed within the marine area are the municipality are unequal in decision making; solutions are proposed from a sectorial perspective, avoiding systems analysis and recognition of coastal complexity within the land use planning process. unequal in decision making; solutions are proposed from sectorial perspective, avoiding systems analysis and recognition of coastal complexity within the marine planning process.

Marine and coastal planning has some Land use planning in coastal municipalities has some multi-sectorial or multi-level coordination actions; few actions; few disciplines have clear disciplines have clear opportunities to influence decision opportunities to influence decision making making and there is variability among management units and there is variability among management and sectors placed within the municipality; solutions are units and sectors placed within the marine very rarely proposed from an integrated or interdisciplinary way, ignoring complexity of coastal component of the land use planning process. area; solutions are very rarely proposed from an integrated or interdisciplinary way, ignoring complexity of coastal component of the marine planning process.

Territorial Planning in Coastal Municipalities has multi-sectorial or multi-level coordination, but rarely both; there are several efforts aimed at supporting equality of opportunities in the decision making among the different disciplines, management units and sectors within the municipality; land use planning solutions usually are proposed from an integrated and interdisciplinary way, although they are rarely based on systems analysis of coastal complexity.
Marine and coastal planning has multi-sectorial or multi-level coordination, but rarely both; there are several efforts aimed at supporting equality of opportunities in the decision making among the different disciplines, management units and sectors within the marine area; solutions usually are proposed from an integrated and interdisciplinary way, although they are rarely based on systems analysis of coastal complexity. 


\section{Continued}

Hydrographic basin management has multi-sectorial and multi-level coordination; there is a clear equality of opportunities in the decision making among the different

10 disciplines, management units and sectors within the river basin; solutions are proposed from an integrated and interdisciplinary way, based on systems analysis of coastal complexity.
Territorial Planning in Coastal Municipalities has multi-sectorial and multi-level coordination; there is a clear equality of opportunities in the decision making among the different disciplines, management units and sectors within the municipality; land use planning solutions are proposed from an integrated and interdisciplinary way, based on systems analysis of coastal complexity.
Marine and coastal planning has multi-sectorial and multi-level coordination; there is a clear equality of opportunities in the decision making among the different disciplines, management units and sectors within the marine area; solutions are proposed from an integrated and interdisciplinary way, based on systems analysis of coastal complexity.

\section{Appendix 2.3. Scoring criteria for modified CoSS framework indicator: participation.}

\begin{tabular}{|c|c|c|c|}
\hline \multirow[b]{2}{*}{ Scoring } & \multicolumn{3}{|c|}{ Planning Instruments } \\
\hline & $\begin{array}{l}\text { Integrated Management of } \\
\text { Hydrographic Basins }\end{array}$ & Territorial Planning in Coastal Municipalities & Marine and Coastal Planning \\
\hline
\end{tabular}

Very few stakeholders are aware or interested in hydrographic basin management; when stakeholders participate, they play a passive or reactive role in finding solutions to address pressures affecting coastal sustainability within the river basin; there is a lack of transparency and evaluation of river basin management programs being implemented in socio-natural coastal systems.
Very few stakeholders are aware or interested in municipal coastal areas; when stakeholders participate, they play a passive or reactive role in finding solutions to address pressures affecting coastal sustainability in their locality; lack of transparency and evaluation of land use plans being implemented in socio-natural coastal systems.
Few stakeholders are aware or interested in coastal linking with marine areas; when stakeholders participate, they play a passive or reactive role in finding solutions to address pressures affecting coastal sustainability linked to marine areas; lack of transparency and evaluation of marine and coastal spatial plans being implemented in socio-natural coastal systems.
Some stakeholders are aware of their role and responsibilities within the management structure of integrated management of hydrographic basins; they rarely play an active or constructive role in solutions to address pressures affecting coastal sustainability within river basin; they rarely promote or demand for transparent participation and evaluation of river basin management programs implemented in socio-natural coastal systems.
Some stakeholders are aware of their role and responsibilities within the coastal component of territorial land use planning structure; they rarely play an active or constructive role in solutions to address pressures affecting coastal sustainability in municipal jurisdiction; they rarely promote or demand for transparent participation and evaluat of land use plans implemented in socio-natural coastal systems.
Some stakeholders are aware of their role and responsibilities within the coastal and marine planning component; they rarely play an active or constructive role in solutions to address pressures affecting coastal sustainability linked to marine areas; they rarely promote or demand transparent participation and evaluation of marine and coastal spatial plans implemented in socio-natural coastal systems.
Key stakeholders are aware of their role and responsibilities within the structure of hydrographic basins management; in most cases they play an active and constructive role in solutions to address pressures

7 affecting coastal sustainability within river basin; they occasionally promote or ask for transparent participation and evaluation of river basin management programs implemented in socio-natural coastal systems.

All stakeholders are aware of their role and responsibilities within the management structure of hydrographic basins management; they play an active and constructive role in solutions addressing pressures in coastal sustainability within river basin; they promote and ask for transparent participation and evaluation of river basin management programs implemented in socio-natural coastal systems.
Key stakeholders are aware of their role and responsibilities within the coastal component of territorial land use planning structure; in most case they play an active and constructive role in solutions to address pressures affecting coastal sustainability in municipal jurisdiction; they occasionally promote or ask for transparent participation and evaluation of land use plans implemented in socio-natural coastal systems.
Key stakeholders are aware of their role and responsibilities within marine and coastal planning structure; in most cases they play an active and constructive role in solutions to address pressures affecting coastal sustainability linked to marine areas; they occasionally promote or ask for transparent participation and evaluation of marine spatial plans implemented in socio-natural coastal systems.
All stakeholders are aware of their role and responsibilities within the coastal component of land use planning structure; they play an active and constructive role in solutions addressing pressures to coastal sustainability in municipal jurisdiction; they promote and ask for transparent participation and evaluation of land use plans implemented in socio-natural coastal systems.
All stakeholders are aware of their role and responsibilities within the coastal component of the marine planning structure; they play an active and constructive role in solutions addressing pressures affecting coastal sustainability linked to marine areas; they promote and ask for transparent participation and evaluation of marine spatial plans implemented in socio-natural coastal systems. 
Appendix 2.4. Scoring criteria for modified CoSS framework indicator: responsibility.

\begin{tabular}{ccc} 
& & Planning Instruments \\
\cline { 2 - 3 } Scoring & $\begin{array}{c}\text { Integrated Management of } \\
\text { Hydrographic Basins }\end{array}$ & $\begin{array}{c}\text { Territorial Planning in } \\
\text { Coastal Municipalities }\end{array}$ \\
\hline
\end{tabular}

River basin management has no legal basis for coastal areas; risk assessments of decisions is nonexistent; socio-ecological coastal systems

$\mathbf{0}$ in river basins are not regulated; organizations involved in ICZM in river basins are indifferent to (directly or indirectly) stewardship and resource efficiency.

Coastal management has no legal basis; risk assessment of decisions is nonexistent; socio-ecological coastal systems are no regulated; organizations involved in ICZM are indifferent to (directly or indirectly) stewardship and resource efficiency.

River basin management has insufficient legal Coastal management has insufficient legal basis for coastal areas; carrying out superficial basis; carrying out superficial risk risk assessments of some of its decisions; few assessments of some of its decisions; few

3 socio-ecological coastal systems in river basins socio-ecological coastal systems are are regulated; organizations involved in ICZM regulated; organizations involved in ICZM in river basins are indifferent to stewardship are indifferent to stewardship and resource and resource efficiency.

Marine and Coastal Planning

Marine and costal planning has no legal basis for coastal areas; risk assessment of decisions is nonexistent; socio-ecological coastal systems are not regulated in land and marine planning; organizations involved in land and marine planning are indifferent to (directly or indirectly) stewardship and resource efficiency in coastal areas.

Marine and costal planning has insufficient legal basis for coastal areas; carrying out superficial risk assessments of some of its decisions; few socio- ecological coastal systems are regulated in land and marine planning; organizations involved in land and marine planning are indifferent to stewardship and resource efficiency in coastal areas.

The legal basis for land and marine planning includes several aspects of coastal areas; land and marine

The legal basis for river basin management includes several aspects of coastal areas; rive basin management occasionally carrying out risk assessments of its decisions; some

Coastal management has legal basis; occasionally carrying out risk assessments of planning occasionally carrying out risk assessments its decisions; some socio- ecological coastal of its decisions; some socio- ecological coastal

7 socio- ecological coastal systems in river basins systems are regulated; organizations involved are regulated; organizations involved in ICZM in ICZM promote stewardship and resource within river basins promote stewardship and efficiency resource efficiency.

systems are regulated in land and marine planning; organizations involved in land and marine planning promote stewardship and resource efficiency in coastal areas.

River basin management has a clear legal basis for coastal areas; shows evidence of carrying out risk assessments of its decisions; socio- ecological coastal systems in river

10 basin are regulated effectively; organizations involved in ICZM within river basins have stewardship and resource efficiency as core criteria.

Coastal management has clear legal basis; shows evidence of carrying out risk assessments of its decisions; socio-ecological coastal systems are regulated effectively; organizations involved in ICZM have stewardship and resource efficiency as a core criteria.
Land and marine planning has a clear legal basis for coastal areas; shows evidence of carrying out risk assessments of its decisions; socio-ecological coastal systems are regulated effectively in land and marine planning; organizations involved in land and marine planning in coastal areas have stewardship and resource efficiency as core criteria.

\section{Appendix 2.5. Scoring criteria for modified CoSS framework indicator: communication.}

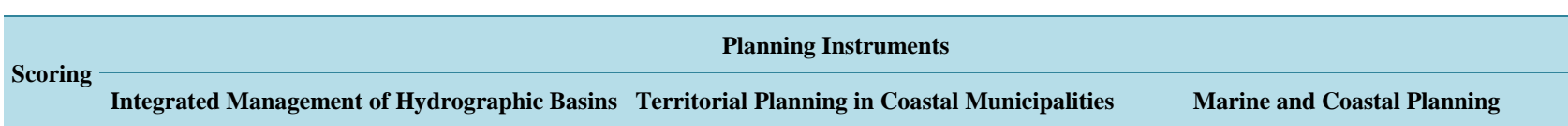

Stakeholders have scarce and incomplete information Stakeholders have scarce and incomplete about river basin management process and its

o socio-ecological coastal systems; communication techniques are always similar and focus only on informing decisions making; communication process is clearly one-way.

Few stakeholders are aware of socio-ecological coastal systems within river basin management; communication techniques are similar among them 3 and rarely have educational goals; stakeholders of river basin management do not recognize socio-ecological coastal systems as a part of their responsibilities.

Majority of stakeholders are aware of socio-ecological coastal systems within river basin socio-ecological coastal systems within land use management; communication techniques are diverse planning; communication techniques are diverse

7 and have some educational goals; coastal river basin and have some educational goals; coastal issues management is usually recognized and operated as a are usually recognized in land use planning which two-way process, using language effectively in the majority of stages. information about land use planning and its socio-ecological coastal systems; communication techniques are always similar and focus only on informing decisions making; communication process is clearly one-way.

Few stakeholders are aware of socio-ecological coastal systems within land use planning; communication techniques are similar among them and rarely have educational goals; stakeholders of land use planning do not recognize socio-ecological coastal systems as a part of their responsibilities.

Majority of stakeholders are aware of

Stakeholders have scarce and incomplete information about marine and coastal planning and its socio-ecological coastal systems; communication techniques are always similar and focus only on informing decisions making; communication process is clearly one-way.

Few stakeholders are aware of socio-ecological coastal systems within marine spatial planning; communication techniques are similar among them and rarely have educational goals; stakeholders of marine and coastal planning do not recognize socio-ecological coastal systems as a part of their responsibilities.

Majority of stakeholders are aware of socio-ecological coastal systems within marine spatial planning; communication techniques are diverse and have some educational goals; coastal issues are usually is operated as a two-way process, using language which is operated as a two-way process, effectively in the majority of stages. using language effectively in the majority of stages. 


\section{Continued}

All stakeholders are aware of socio-ecological coastal components of river basin management; communication techniques are diverse and have clear educational goals; coastal river basin management is recognized and operated as a two-way process, using language effectively at all stages.
All stakeholders are aware of socio-ecological coastal systems within land use planning; communication techniques are diverse and have clear educational goals; coastal issues are always recognized in land use planning and it operated as a two-way process, using language effectively at all stages.
All stakeholders are aware of socio-ecological coastal systems within marine and coastal planning; communication techniques are diverse and have clear educational goals; coastal issues are always recognized in marine spatial planning which is operated as a two-way process, using language effectively at all stages.

Appendix 2.6. Scoring criteria for modified CoSS framework indicator: balance.

\begin{tabular}{|c|c|c|c|}
\hline \multirow{2}{*}{ Scoring } & \multicolumn{3}{|c|}{ Planning Instruments } \\
\hline & $\begin{array}{l}\text { Integrated Management of } \\
\text { Hydrographic Basins }\end{array}$ & $\begin{array}{c}\text { Territorial Planning in Coastal } \\
\text { Municipalities }\end{array}$ & Marine and Coastal Planning \\
\hline
\end{tabular}

River basin management in coastal areas is done without taking into account "social fairness"; environmental quality in coastal areas is assessed only from ecological perspective, and analysis of costs and benefits are nonexistent; stakeholders within river basins do not perceive the trade-offs stemming from management decisions in coastal river basins.

River basin management in coastal areas occasionally takes into account "social fairness"; environmental quality assessments in coastal areas slightly include economic perspective; analysis of costs and benefits are focused on only one perspective (economic, social or environmental); some stakeholders within river basin perceive the trade-offs stemming from integrated management decisions in coastal river basins.
Land use planning is done without taking into account "social fairness" in coastal areas; coastal environmental quality is assessed only from ecological perspective, and analysis of costs and benefits are nonexistent; stakeholders do not perceive the trade-offs stemming from management decisions of coastal land use.
Marine and coastal planning is done without taking into account "social fairness" in coastal areas, and environmental quality is assessed only from ecological perspective; analysis of costs and benefits is nonexistent in marine spatial planning; stakeholders do not perceive the trade-offs stemming from management decisions of marine activities on coastal areas.

Land use planning occasionally takes into Marine and coastal planning occasionally account 'social fairness' in coastal areas; takes into account "social fairness" in coastal coastal environmental quality assessments areas, and environmental quality assessments slightly include economic perspective, and slightly include economic perspective; Marine analysis of costs and benefits are focused spatial planning analyses costs and benefits on only one perspective (economic, social only for one perspective (economic, social or or environmental); some stakeholders perceive the trade-offs stemming from integrated decisions of coastal land use. environmental); some stakeholders perceive the trade-offs stemming from management decisions of marine activities on coastal areas.

River basin management in coastal areas takes into account "social fairness" in majority of its decisions; decision making enhances environmental quality in coastal areas with regard its impact upon employment and

7 income; river basin management considers the consequent costs and benefits for socio-ecological coastal systems, and most stakeholders perceive the trade-offs stemming from integrated management decisions in coastal river basins.
Land use planning takes into account "social fairness" in majority of its decisions in coastal areas, and enhances environmental quality with regard its impact upon employment and income; land use planning considers the consequent costs and benefits for socio-ecological coastal systems; most stakeholders perceive the trade-offs stemming from integrated decisions of coastal land use.
Marine and coastal planning takes into account "social fairness" in majority of its decisions in coastal areas, and enhances environmental quality with regard its impact upon employment and income; Marine spatial planning considers the consequent costs and benefits for socio-ecological coastal systems; most stakeholders perceive the trade-offs stemming from management decisions of marine activities on coastal areas.
River basin management in coastal areas has a commitment to take into account "social fairness"; decision making protects and enhances optimum environmental quality in coastal areas with regard to its impact upon employment and income; river basin management considers and negotiates the consequent costs and benefits for socio-ecological coastal systems, and stakeholders perceive and understand the trade-offs stemming from integrated management decisions in coastal river basins.
Land use planning has a commitment to take into account "social fairness" in coastal areas, and protects and enhances optimum environmental quality with regard to its impact upon employment and income; land use planning considers and negotiates the consequent costs and benefits for socio-ecological coastal systems; stakeholders perceive and understand the trade-offs stemming from integrated decisions of coastal land use.
Marine and coastal planning has a commitment to take into account "social fairness" in coastal areas, and protects and enhances optimum environmental quality with regard to its impact upon employment and income; Marine spatial planning considers and negotiates the consequent costs and benefits for socio-ecological coastal systems; stakeholders perceive and understand the trade-offs stemming from management decisions of marine activities on coastal areas. 